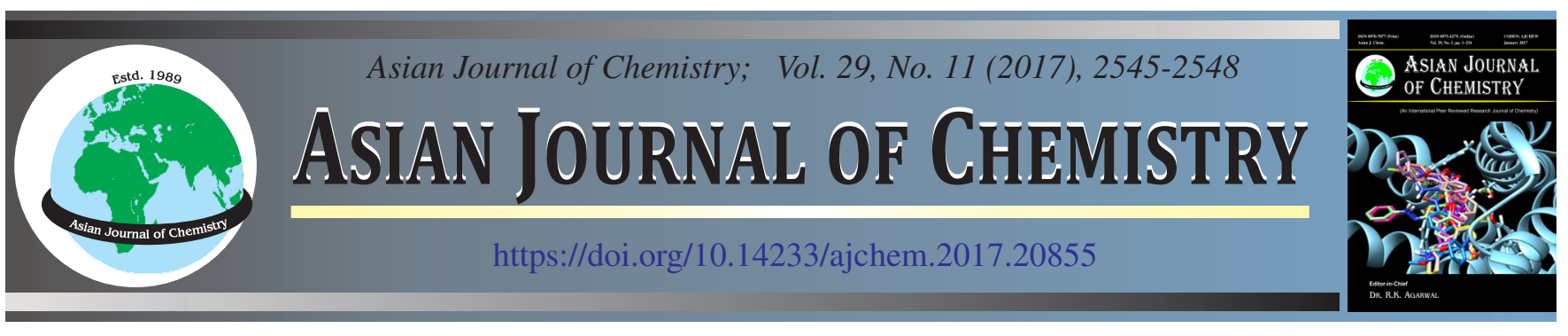

\title{
Synthesis of Polyaniline Based Nanocomposite Graphite Paste Electrode Modified with and Without Rice Husk for Sensor Application: A Comparative Study
}

\author{
K.S. PaithanKaR ${ }^{1, *}$, V.B. Deshmukh ${ }^{1}$, U.N. ShelKe ${ }^{1}$, S.B. IyYeR ${ }^{1}$, S.T. More ${ }^{2}$ and V.K. GAde ${ }^{3}$
}

\author{
${ }^{1}$ Department of Physics Research Center, Ahmednagar College, Ahmednagar-414 001, India \\ ${ }^{2}$ Department of Physics, Institute of Technology, Kuran, Pune-410 511, India \\ ${ }^{3}$ Department of Physics, Shri Anand College, Pathardi-414 102, India \\ *Corresponding author: E-mail: paithankar86@gmail.com
}

Received: 10 June 2017;

Accepted: 16 August 2017;

Published online: 29 September 2017;

AJC-18589

Polyaniline based nanocomposite graphite paste electrode modified with rice husk (PANI/Gr/RH) and without rice husk (PANI/Grph) to
compare the amperometric response caused by the addition of rice husk in conventional sensor. Organized materials were characterized
by analytical techniques such as UV-visible, XRD and FE-SEM analyses. The performance of the developed sensor was evaluated and the
obtained urea biosensor exhibited shorter response time $(3 \mathrm{~s})$, wider range $1 \times 10^{-9}$ to $9 \times 10^{-9} \mathrm{M}$ and the detection limit were found to be
$1 \times 10^{-9}$. About $90 \%$ of the enzyme activity is retained for about 40 days. Modified rice husk sensor gives better result than sensor without
rice husk.

Keywords: Amperometric, Biosensor, Rice husk, Nanocomposite, Polyaniline.

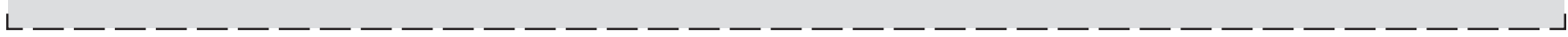

\section{INTRODUCTION}

In the present work, we report the performance of a graphite paste electrode (GPE) modified by a rice husk (RH), which is to be a good adsorbent for analyte, for detecting of urea in laboratory samples using amperometric technique with addition of polyaniline a good conducting polymer supporting to graphite paste. This rice husk modified electrode compare with simple graphite polyaniline based electrode by measuring amperometric response caused by the immobilized urease reaction system. The electrochemical cell was assembled in a conventional one compartment three electrode system design, the working electrode was modified paste electrode consist of composition of 70:22:5:3 (graphite: mineral oil: polyaniline: rice husk) this paste allowed to homogenize for few hours [1]. The paste was then filled in a Teflon tip. A platinum wire was dissected inside the paste, to provide an electrical contact. Smooth and fresh electrode surfaces were obtained by pressing out $0.5 \mathrm{~mm}$ of paste from the syringe, scraping off the excess and polishing it by butter paper until the surface has a shiny look and polyaniline composite in which the urease immobilized; the $\mathrm{Ag} / \mathrm{AgCl}$ used as the reference electrode; and a graphite use as the counter electrode. The superior performance rice husk modified graphite paste electrode (PANI/Gr/RH) is demonstrated by the speciation and detection of urea forms in pharmaceutical formulations, urine sample, sea water samples [2]. The proposed potentiometric method has been validated by using inductively coupled plasma-atomic emission spectrometry (ICP-AES). To the best of our knowledge, this is the second instance wherein rice husk has been employed as a modifier for sensing method [3-6]. The role of PANI is that to provide conductivity.

Urea is an imperative analyte utilized as a part of blood and urine examination. Up to this point, numerous sorts of poten-tiometric urea sensors utilizing urease have been created [7-11]. The discovery standards of potentiometric urea sensors depend on the adjustments in $\mathrm{pH}$ and the convergence of smelling salts or carbon dioxide delivered amid urease responses. In this way, these sensors use the $\mathrm{pH}$-delicate glass or field-impact transistor anodes and gas detecting cathodes outfitted with smelling salts or carbon dioxide penetrable layer as the location gadgets. These sensors are affected by the impedance because of alkali and pH changes. Then again, moderately few amperometric urea sensors in view of recognition of alkali have been accounted for [12-15]. Numerous amperometric biosensors of urea in view of immobilization of urease in directing polymers have likewise been created [16-23]. These sensors are meddled by alkali. Another sort of amperometric urea sensor depends on the $\mathrm{pH}$-subordinate anode oxidation of hydrazine [24,25]. Smelling salts creation changes $\mathrm{pH}$ and a large portion of traditional ampere metric urea sensors experience the ill effects of the obstruction of alkali. 
It is notable that urea is changed over to smelling salts and carbon dioxide through carbamic corrosive. The recognition rule of the amperometric urea identification in light of the urease catalyzed hydrolysis of urea. Carbamic corrosive and smelling salts are the underlying enzymatic response results of urea and carbamic corrosive is additionally hydrolyzed to alkali and carbon dioxide. The last items (alkali and carbon dioxide) are electroinactive; subsequently, if an oxidation current is seen amid the enzymatic response, the middle item should be electrolyzed. In our past review [24,26], one of the last anode response results of urea amid electrolysis has as of now been affirmed to nitrogen. Further, it can be accepted that carbamic corrosive experiences three electrons oxidation to frame nitrogen and carbon dioxide.

\section{EXPERIMENTAL}

Urea (99\%), urease was purchased from Sigma Aldrich, Graphite fine powder extra pure (particle size $240 \times 10^{-6} \mathrm{~m}$ ) obtained from Loba chemie Pvt. Ltd. India, Paraffin liquid heavy or mineral oil (viscosity at $37{ }^{\circ} \mathrm{C}$ is $64 \mathrm{cS}$ ) purchased from High purity lab, Mumbai, India. UV-visible spectra were recorded in air at room temperature in the wavelength range of 200-800 nm using a Jena specord 210 spectrophotometer. FT-IR spectra were recorded on a Ocean optics HPX-2000 (Fiber coupled) spectrometer in the range of $4000-500 \mathrm{~cm}^{-1}$. FE-SEM carried by JEOL JSM-7500F. Amperometric response characteristics were studied with a $4^{1 / 2}$ Digit True RMS Multimeter (MODEL 1085).

Method of treating rice husk: Rice husk was dried under sun and impurities were separated manually. It was boiled with distilled water for $2 \mathrm{~h}$ to make it free from coloured compounds. It was then filtered. The residual material so obtained was dried at $80{ }^{\circ} \mathrm{C}$ in hot air oven for $24 \mathrm{~h}$. RH thus treated was ground till fine particles in the range of $1-10 \mathrm{~m}$ are obtained. The material was stored in an airtight glass vial for further use. This powdered rice husk was employed as a modifier in the graphite paste electrode [1]. It is to be noted here that the composition of rice husk varies from one vegetable species to another or even depending on the time at which harvest process is carried out. It is expected that its adsorptive behaviour for urea would not change drastically.

\section{RESULTS AND DISCUSSION}

SEM study: As shown in Fig. 1(a-b) the sensor electrode made with and without rice husk distinctly shows difference in surface morphology. Fig. 1(a) (PANI/Gr) without rice husk porous globular structure is observed. In contrast, in presence of rice husk Fig. 1(b) (PANI/Gr/RH) with crystalline particles sharp edges of rice husk are clearly observed. Hence, it is expected that rice husk will contribute to the adsorption of enzymes and polyaniline will form a complex with it. This synergistic effect will lead to a better performance of PANI/ $\mathrm{Gr} / \mathrm{RH}$ as compared to PANI/Gr.

UV-visible study: Fig. 2(a-b) shown the optical absorption spectrum of synthesized PANI/Gr/RH (a) and PANI/Gr (b) electrode. The spectrum recorded in directly without any solution on it. All spectra were recorded in the wavelength range of $300-800 \mathrm{~nm}$. The shoulder is appearing at $491 \mathrm{~nm}$ corresponds to the formation of ES (Emeraldine salt) phase irrespective of their organic supporting electrolyte. It shows very good resemblance with earlier reported work [7,8]. Fig. 2(b) shown peak is just shifted at $499 \mathrm{~nm}$.

XRD study: XRD pattern of (PANI/Gr/RH) shows in Fig. 3. It is clearly indicates that the intensity of observed peaks are better developed on the composites prepared using di and tri basic acid solutions compared with the monobasic acid. The profile of the characteristic peak of PANI at $\approx 25^{\circ}$. Thus the fraction of crystalline phase found to be increased as increasing the voltages. XRD of (PANI/Gr/RH) exhibited the characteristic cubic (FCC) diffraction peaks at $22^{\circ}$. The XRD pattern of purified (PANI/Gr) with rice husk is shifted at $23^{\circ}$.

Current response: Fig. 4(a-b) shows the current response for various concentration of urea. Fig. 4(a) shows amperometric response for PANI/Gr/RH and Fig. 4(b) shows response for PANI/Gr. When the potential of the enzyme electrode was set at $0.7 \mathrm{~V}$ is as shown in Fig. 4. It was found that the response current of the enzyme electrode easily reaches to steady state.
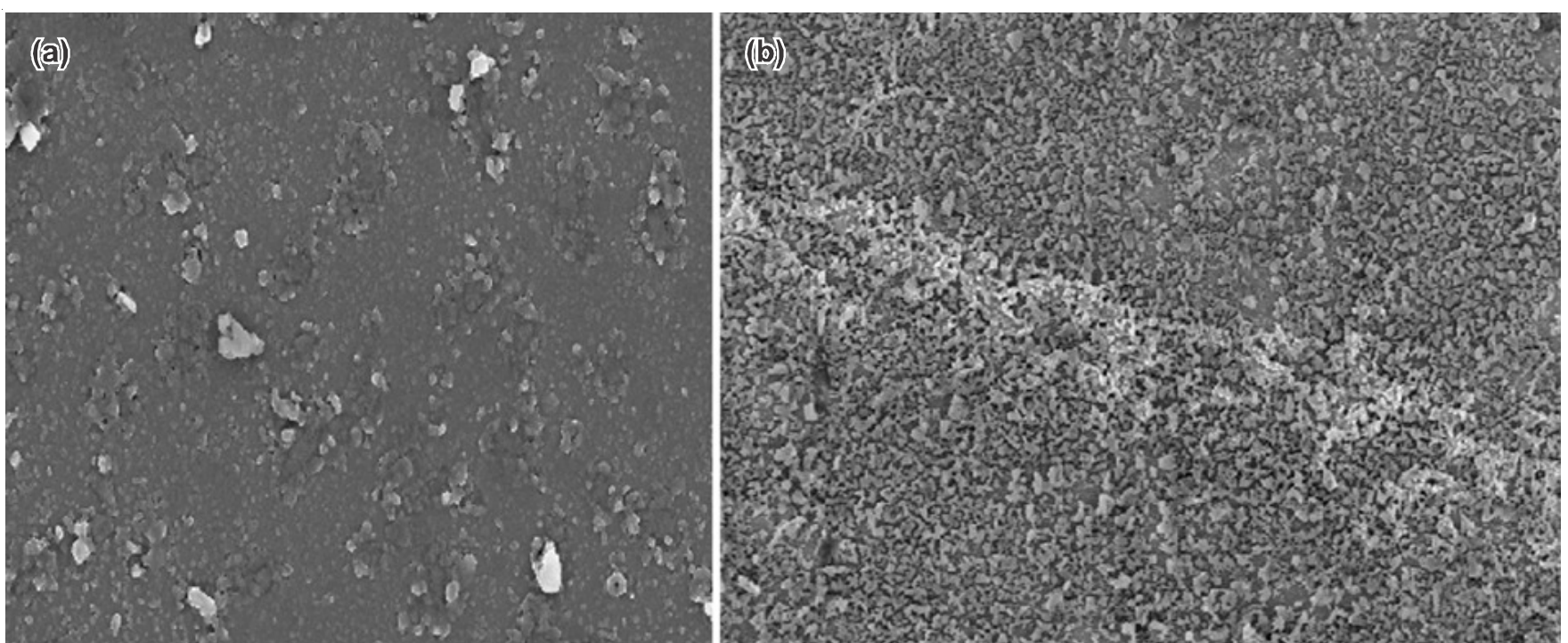

Fig. 1(a-b). SEM of (a) PANI/Gr (Mag.25KX) and (b) PANI/Gr/RH (Mag.25KX) 


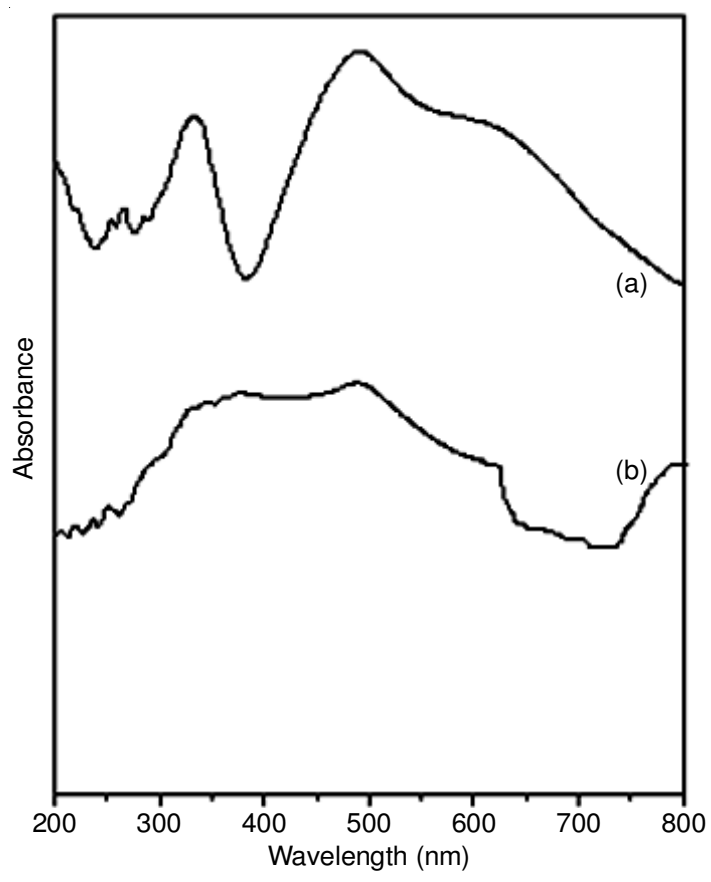

Fig. 2(a-b). UV-visible study of (a) PANI/Gr/RH (b) PANI/Gr

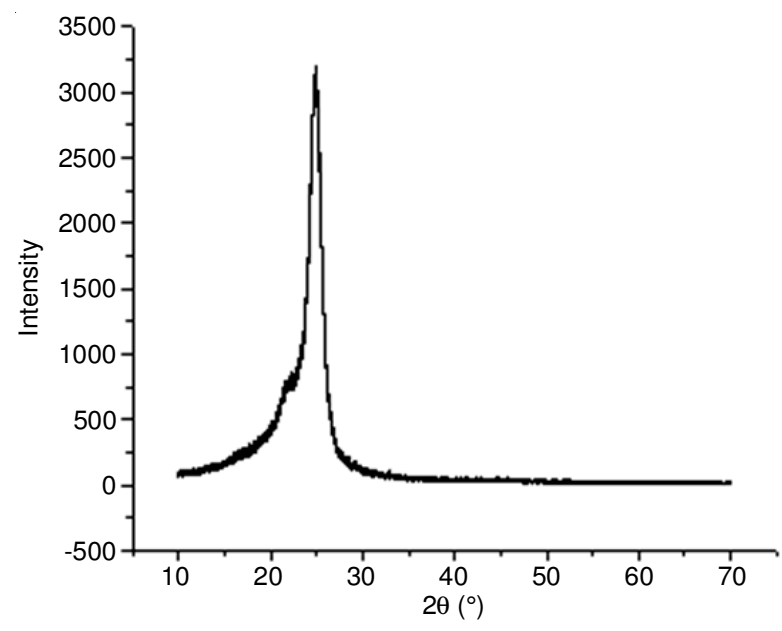

Fig. 3. XRD study of PANI/Gr/RH

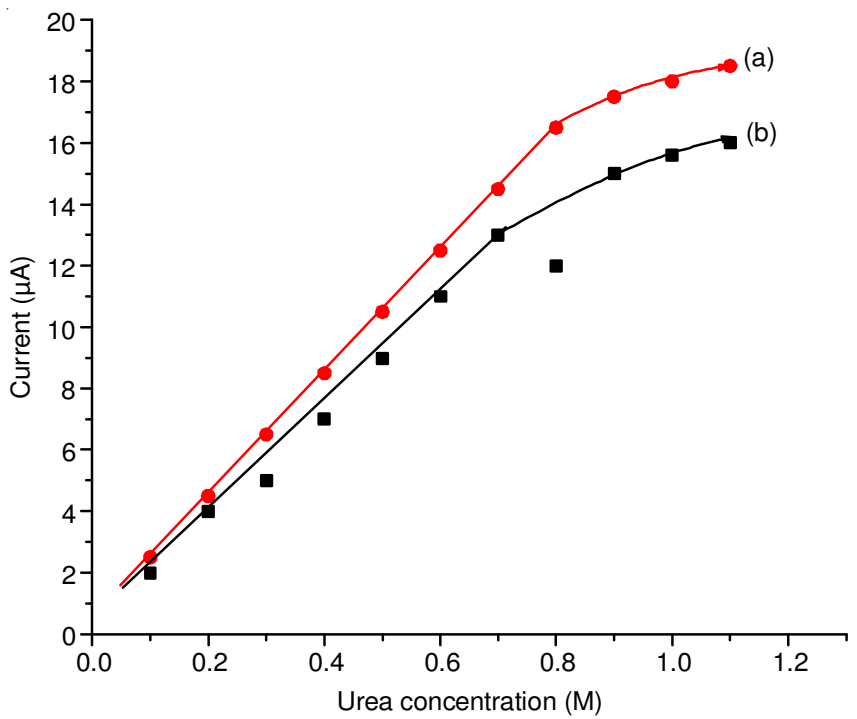

Fig. 4a-b. Current-concentration curve (a) PANI/Gr/RH (b) PANI/Gr at $0.7 \mathrm{~V}$ and $\mathrm{pH} 7$ in $0.1 \mathrm{M}$ PBS for different urea solution of $0.1 \times$ $10^{-9}$ to $1.1 \times 10^{-9} \mathrm{M}$
The relationship between response current and urea concentration in $0.1 \mathrm{M}$ phosphate buffer $\mathrm{pH} 7$ is shown. It was found that, current increases with increasing urea concentration in the range of $0.1 \times 10^{-9}$ to $1.1 \times 10^{-9} \mathrm{M}$. Amperometric response of PANI/Gr/RH (a) is larger than PANI/Gr (b) electrode In the present case, assuming that the enzyme is uniformly distributed throughout the electrode, the reaction takes place predominantly on the surface of the electrode in the lower concentration. Platinum wire help in oxidation process therefore no secondary enzymes required for oxidation, when urea is oxides ammonia is formed and it does not take part in reaction. However, the reaction on the surface of the electrode and the diffusion occurring simultaneously at higher concentrations delays the response time. With increasing concentrations of urea, the response current also increased and finally reached to steady state value. Fig. 5(a-b) shows the steady-state potential dependence calibration curve for the each individual urea concentration [Fig. 5(a)]. The response of PANI/Gr/RH to urea was found to be wide linear range of $2 \times 10^{-9}$ to $8 \times 10^{-9} \mathrm{M}$ and for Fig. 5(b) PANI/Gr it become very short $3 \times 10^{-9}$ to $6 \times 10^{-9}$ $\mathrm{M}$. This linearity range is in well conformity with that obtained in the amperometric response of sensor is proper in proportion to urea concentration.

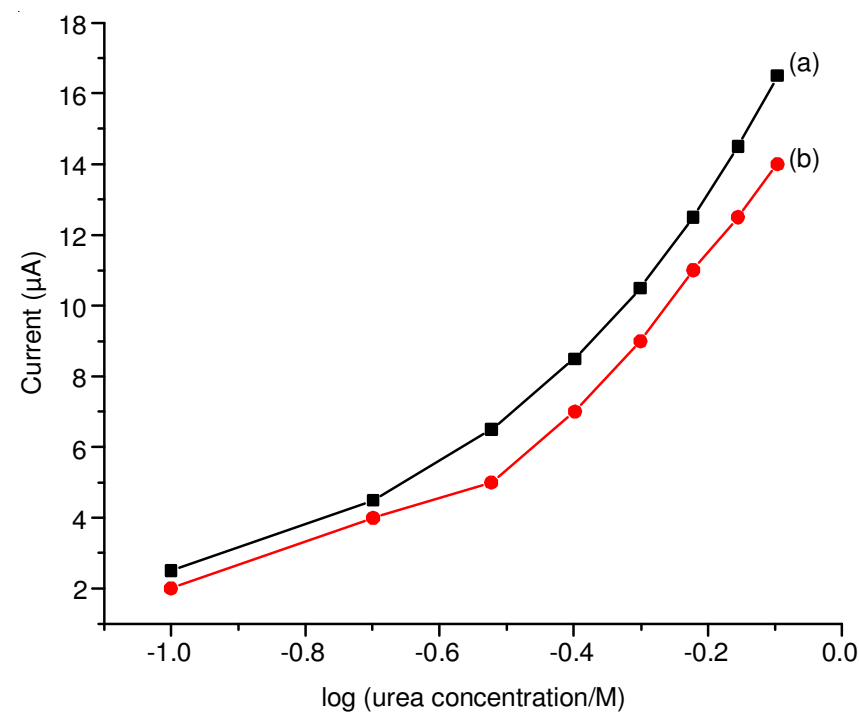

Fig. 5(a-b). Steady-state potential dependence calibration curve of biosensor (a) PANI/Gr/RH (b) PANI/Gr

Storage stability: Long term stability is one of the most important features required for the satisfactory application of a biosensor as shown in Fig. 6 In order to evaluate the storage stability, the both sensor was tested for 40 days of storage in $0.1 \mathrm{M}$ phosphate buffer $\mathrm{pH} 7$ at $20^{\circ} \mathrm{C}$. There is a slight decrease in sensitivity of the sensor (PANI/Gr/RH) of about $10 \%$ from the initial value, revealing a very good preservation of the bioactivity than sensor without rice husk (PANI/Gr) [27]. Fine structure if rice husk provide the mechanical strength to sensor.

\section{Conclusion}

A PANI/Gr/RH electrode has been developed and successfully employed for the urea determination laboratory sample. A detection limit of $0.1 \times 10^{-9} \mathrm{M}$ for urea was achieved with the use of the PANI/Gr/RH. This method gives benefits such 


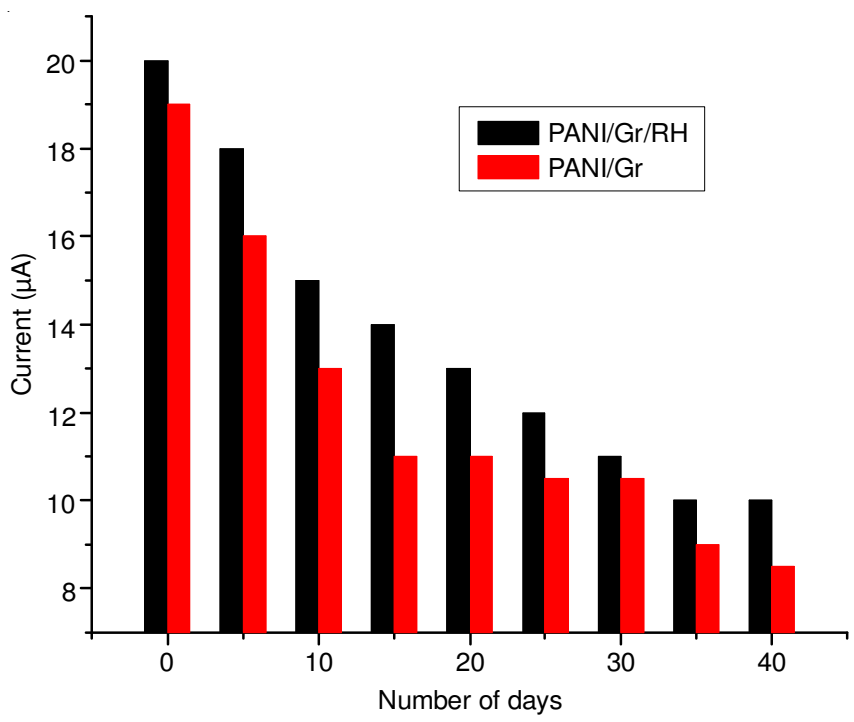

Fig. 6. Stability of the (a) PANI/Gr/RH (b) PANI/Gr. electrode on storage in $0.1 \mathrm{M}$ PBS ( $\mathrm{pH} 7$ ) for 40 days

advantages as high sensitivity, low detection limit, easy handling, resistance against surface fouling and low cost. Consequently, this method is recommended for the analyses of phosphate, antimony, glucose, creatinine in clinical as well as quality control laboratories.

\section{ACKNOWLEDGEMENTS}

The authors are thankful to Department of Chemistry and Department of Physics, Savitribai Phule Pune University, India for providing the laboratory facility.

\section{REFERENCES}

1. I. Svancara, K. Vytras, K. Kalcher, A. Walcarius and J. Wang, Electroanalysis, 21, 7 (2009);

https://doi.org/10.1002/elan.200804340.

2. N.S. Gadhari, B.J. Sanghavi and A.K. Srivastava, Anal. Chim. Acta, 703, 31 (2011);

https://doi.org/10.1016/j.aca.2011.07.017.

3. B. Lakard, G. Herlem, S. Lakard, A. Antoniou and B. Fahys, Biosens. Bioelectron., 19, 1641 (2004); https://doi.org/10.1016/j.bios.2003.12.035.

4. A. Sehitogullari and A.H. Uslan, Talanta, 57, 1039 (2002); https://doi.org/10.1016/S0039-9140(02)00149-2.

5. S.B. Adeloju, S.J. Shaw and G.G. Wallace, Anal. Chim. Acta, 281, 621 (1993); https://doi.org/10.1016/0003-2670(93)85023-D.

6. A. Sassolas, B. Prieto-Simón and J.-L. Marty, Am. J. Anal. Chem., 3, 210 (2012); https://doi.org/10.4236/ajac.2012.33030.
7. G.G. Guilbault and J.G. Montalvo, J. Am. Chem. Soc., 92, 2533 (1970); https://doi.org/10.1021/ja00711a052.

8. E. Bakker and M.E. Meyerhoff, eds.: A.J. Bard, M. Stratmann and G.S. Wilson, Ion-Selective Electrodes for Measurements in Biological Fluids, In: Encyclopedia of Electrochemistry, Wiley-VCH, Weinheim, vol. 9 (2002).

9. S. Uchiyama, M. Kobayashi and Y. Hasebe, Electroanalysis, 14, 1644 (2002); https://doi.org/10.1002/elan.200290005.

10. R. Sahney, B.K. Puri and S. Anand, Anal. Chim. Acta, 542, 157 (2005); https://doi.org/10.1016/j.aca.2005.03.069.

11. P. Bertocchi, D. Compagnone and G. Palleschi, Biosens. Bioelectron., 11, 1 (1996); https://doi.org/10.1016/0956-5663(96)83708-0.

12. M. Senda and Y. Yamamoto, Electroanalysis, 5, 775 (1993); https://doi.org/10.1002/elan.1140050910.

13. K. Yoneyama, Y. Fujino, T. Osaka and I. Satoh, Sens. Actuators B Chem., 76, 152 (2001); https://doi.org/10.1016/S0925-4005(01)00613-X.

14. W.J. Cho and H.J. Huang, Anal. Chem., 70, 3946 (1998); https://doi.org/10.1021/ac980004a.

15. V. Rajesh, W. Bisht, W. Takashima and K. Kaneto, Biomaterials, 26, 3683 (2005). https://doi.org/10.1016/j.biomaterials.2004.09.024.

16. M. Trojanowicz, A. Lewenstam, T.K.V. Krawczyk, I. Lahdesmaki and W. Szczepek, Electroanalysis, 8, 233 (1996); https://doi.org/10.1002/elan.1140080307.

17. P.C. Pandey and A.P. Mishra, Analyst, 113, 329 (1988); https://doi.org/10.1039/an9881300329.

18. B.E.Y.Yon Hin, R.S. Sethi and C.R. Lowe, Sens. Actuators, 1, 550 (1990); https://doi.org/10.1016/0925-4005(90)80271-Z.

19. S.B. Adeloju, S.J. Shaw and G.G. Wallace, Anal. Chim. Acta, 341, 155 (1997); https://doi.org/10.1016/S0003-2670(96)00502-8.

20. S.B. Adeloju, S.J. Shaw and G.G. Wallace, Anal. Chim. Acta, 323, 107 (1996); https://doi.org/10.1016/0003-2670(95)00562-5.

21. I. Vostiar, J. Tkac, E. Sturdik and P. Gemeiner, Bioelectrochemistry, 56, 113 (2002); https://doi.org/10.1016/S1567-5394(02)00042-7.

22. D. Kirstein, L. Kirstein and F. Scheller, Biosensors, 1, 117 (1985); https://doi.org/10.1016/0265-928X(85)85007-0.

23. D. Kirstein, F. Scheller, B. Olsson and G. Johansson, Anal. Chim. Acta, 171, 345 (1985); https://doi.org/10.1016/S0003-2670(00)84213-0.

24. S. Uchiyama, H. Watanabe, H. Yamazaki, A. Kanazawa, H. Hamana and Y. Okabe, J. Electrochem. Soc., 154, F31 (2007); https://doi.org/10.1149/1.2402127.

25. D.K. Bandgar, G.D. Khuspe, R.C. Pawar, C.S. Lee and V.B. Patil, Appl. Nanosci., 4, 27 (2014); https://doi.org/10.1007/s13204-012-0175-8.

26. S.K. Shukla, A. Bharadvaja, A. Tiwari, G.K. Parashar and G.C. Dubey, Adv. Mater. Letts., 1, 129 (2010). https://doi.org/10.5185/amlett.2010.3105.

27. V.K. Gade, D.J. Shirale, P.D. Gaikwad, P.A. Savale, K.P. Kakde, H.J. Kharat and M.D. Shirsat, React. Funct. Polym., 66, 1420 (2006); https://doi.org/10.1016/j.reactfunctpolym.2006.04.005. 